\title{
DOS NOVELISTAS VERACRUZANOS
}

\author{
PO R
}
CLE M E N TINA
D I A Z Y
D $\mathbf{E}$
O V A N O

E LAS visiones de conjunto de la Literatura Mexicana son aludidos muy Covar encima dos escritores veracruzanos: el romántico Juan Diaz Covarrubias y el realista Cayetano Rodriguez Beltrán; pero basta revisar su obra para darnos cuenta que tienen verdadero interés para nuestra literatura, motivo por ef cual pretendo, destacar aquí algunos de sus aspectos
más positivos.

En una pobre y destartalada buhardilla, la que José María Lacunza habitaba en el Colegio de San Juan de Letrán, se leyeron las primeras composiciones plenamente románticas.

El sitio, el ambiente de la recién fundada Academia de Letrán que con tanta gracia describe en sus Memorias Guillermo Prieto, estaban muy de acuerdo con la nueva escuela que entraba de lleno a nuestras letras pues todas las circunstancias la favorecían: como consecuencia de las luchas 
de Independencia nada se quería con España, era natural que considerado el Romanticismo fruto de la Revolución francesa se le diese preferencia. Además, el profundo individualismo que heredamos de España exagerado por las diferencias étnicas; nuestra tradicional pereza que trae consigo la falta de preparación literaria; la indisciplina para el trabajo sistemático; nuestro gusto por el color; nuestro idealismo -característica iberoamericana- y el sentimiento que desde siempre ha sido nuestra más auténtica expresión eran otros tantos factores que propiciaron el triunfo y la persistencia del Romanticismo; todavía los precursores del Modernismo son románticos y el hálito de esta escuela se advierte aun en las composiciones populares.

Los caracteres más salientes de esta escuela: individualismo, sentimentalismo, idealismo, amor a la naturaleza, a la patria, interés por la historia y la forma descuidada se dan junto con los temas tratados por el Romanticismo en la escasa obra de uno de los primeros románticos, Juan Diaz Covarrubias. No es, desde luego, una de las figuras más relevantes, pero su vida, su muerte y su obra auténticamente románticas lo hacen muy digno de estudio.

En la hermosa ciudad de Jalapa nació el 27 de diciembre de 1837 el poeta. Su padre, el general José de Jesús Covarrubias también cultivó la poesía, antes que Guillermo Prieto hizo romances históricos, género importantísimo que al decir del maestro Ignacio M. Altamirano "crea la epopeya en una de sus varias formas". Diez Covarrubias dice refiriéndose a los romances de su padre: "Era mi padre el poeta más querido de Jalapa, aquel cuyos romances todavía se recitan en el hogar, cuyos versos se recitan en las noches de luna o en las reuniones populares". 1

El poeta, romántico hasta los tuétanos, habla de su nacimiento señalado por el infortunio, por la desdicha, constantes compañeras de su vida:

\footnotetext{
Yo nací cuando el luto desolaba con su martirio, funeral, eterno, el dulce asilo del hogar paterno, y el infortunio me nutrió con hiel. En oscuro destierro, abondonado, lejos lloraba mi doliente padre,
}

1 Obras Completas de Juan Díaz Covarrubias. México: Tipografía de M. Castro. 1859 , p. 233. 
y lloraba también mi pobre madre, mi tierna madre, tan amante $y$ fiel...2

Muy pequeño Díaz Covarrubias queda huérfano. La familia se radica en México y en esta ciudad se matricula en el Colegio de Letrán. Sus inclinaciones van hacia la medicina. Pronto sufre los desengaños de la pasión amorosa: amar y no ser correspondido.

Versos, novelas, artículos todo bajo el signo que pudiéramos llamar romántico catastrófico fueron la puerta evasión de este escritor melancólico, de un pesimismo tan agudo que es comparable al de Mariano José de I.arra. Siempre triste. Emplazado por la muerte.

Diaz Covarrubias a quien sublevaba la injusticia, para quien la patria fue una preocupación constante, angustiosa, casi obsesiva, no pudo menos de afiliarse a la causa - para mi- la más noble, la más justa, la de visión más acertada, la causa que defendía el partido liberal y para defenderla se entró a las filas liberales a atender heridos y esta actitud apasionadamente romántica lo entregó a la muerte el 10 de abril de 1859. El crimen recae sobre el partido conservador y sobre aquel que desde entonces es motejado como "la hiena de Tacubaya", Leonardo Márquez.

Ia mejor semblanza del infortunado poeta la deja su contemporáneo Ignacio M. Altamirano:

"Aquella vaga tristeza que no parecía sino el sentimiento agorero de su trágica y prematura muerte, aquella inquietud de un alma que no cabía en su estrecho límite humano, aquelia sublevación instintiva contra una sociedad viciosa que al fin había de acabar por sacrificarle, aquella sibila de dolor que se agitaba en su espíritu pronunciando quién sabe qué oráculos siniestros, aquella pasión ardiente y vigorosa que se desbordaba como lava encendida de $\mathrm{s}$ corazón; he aquí la poesía de Juan Diaz Covarrubias, he aquí sus novelas". "

Su obra fue escrita en tiempo tormentoso, poco propicio a las letras, como el poeta mismo advierte: "Sólo un niño o un loco piensa en escribir en México en esta época aciaga de desmoronamiento social, y pretender ser lé́do a la luz rojiza del incendio y al estruendo de los cañones". Obra

2 Juan Diaz Covarrubias. Impresiones y Sentimientor. Escenas y costumbres mexicanas. México. Tipografia de Manuel Castro. 1859. p. 79.

3 Ignacio M. Altamirano. La Literatura Nacional. Edit. Porrúa. México, 1949. Tomo I. p. 50. 
de juventud, fruto en agraz que prometia si hubiese sazonado un mejor y delicioso sabor mexicano, se reunió y publicó el mismo año de su muerte.

EI poeta había vivido escasamente veintidós años. Una novela histórica Gil Gómez el Insurgente o La Hija del Médico y las novelas La Sensitiva, La Clase Media, El Diablo en México, Impresiones y gentimientos; un pequeño volumen de poesías Paginas del Corazón, constituyen su acervo literario.

Entre las muchas novedades y revalorizaciones que el Romanticismo trajo consigo está, con el drama, la novela; pero no la novela a secas sin adjetivo preciso que la limite, sino la ceñida por normas y motivos precisos: la novela histórica. Novela y dramas históricos fueron con este movimiento acicates del quehacer y pensar históricos. La novela de esta índole empezó a cultivarse en Inglaterra, Francia y Alemania, antes del advenimiento de la escuela romántica para alcanzar con esta su afirmación universal; y pretendía vueltos los ojos al pasado, ya fuese a la Edad Media, al Renacimiento, a la América de Moctezuma o a la de los Virreyes, representar el "espíritu de una época" e infundir nuevo aliento a formas de vida ya caducas para dar una verdad más humana que la otorgada por la historia documental. Pues la historia, dirá un escritor romántico, Hermann Kurz, en 1843 "no nos da más que un conocimiento fragmentario, de instantáneas y no de movimiento, lleno de lagunas y puntos muertos, en cambio, el poeta conoce el espíritu que reina en tradiciones antiguas, $y$ puede colorear y vivificar los grises esquemas". "

$Y$ a decir verdad, no andaban tan errados los románticos como a primera vista parece, ya que este traernos la conciencia del pasado en el presente, es uno de los valores de toda obra auténtica y lo hace, desde luego, la novela histórica.

Estas ideas y otras análogas, todas en defensa de la novela histórica tenían los escritores románticos cuando con Walter Scott a la cabeza se lanzaron a la reconstrucción del pasado con la afirmación de serle fieles a la historia y a partir de la publicación de Ivanhoe (1819), la novela histórica alcanzó enorme éxito en Europa y en América.

Los emigrados españoles que a la sazón huían del tirano Fernando VII traducen en 1825 las novelas del escritor escocés y desde luego se hacen en España y en América imitaciones y adaptaciones de ellas. Estas primeras traducciones de los "emigrados españoles aparecieron simultánea-

4 Citado por Amado Alonso en su libro Emsayo sobre la movela histórico. Buenos Aires. 1942. p. 81. 
mente en las librerias de Londres y México. En México y en Lima se hicieron $y$ se representaron adaptaciones teatrales de las novelas de Walter Scott, y en La Habana, 1838 , se tradujo y se publicó El cuarto entapizado por Juan Muñoz de Castro"; " pero como en América no existían los elementos medievales -armazón de la novela scottiana- los escritores americanos prefirieron seguir a Dumas, a Sué o al español Fernández y Gonlez quien escribe novelas demasiado largas, de escasa calidad literarja, que valen, sin embargo, por la reconstrucción histórica y fueron muy gustadas y alabadas en México. Ignacio M. Altamirano, en Fevista Literaria, 1868, hace una elogiosa crítica a Fernández y González, le otorga grandes cualidades y habla del éxito que sus obras obtuvieron en México.

Muy pronto los eruditos demostraron que el idolo Walter Scott $y$ sus seguidores habian calabaceado a la tan traida y llevada "exactitud histórica"; ayudados por la fantasía adobaban la historia a su sabor; a Leopoldo von Ranke cumbre máxima de la historiografía del siglo xix, disgustaban sobremanera las desviaciones que a manos románticas sufrian las figuras históricas, fallas que claramente se advierten en el Quentin Durzuard; pero si Ranke objeta la imaginativa historia romántica llena de vida, la critica de hoy, hecha por Edmundo $O^{\prime}$ Gorman en su libro Crisis y Porvenir de la Ciencia Histórica ${ }^{\circ}$ demuestra que esa campanuda historia científica hinchada de documentación y que alardeaba de poseer la verdad absoluța es del todo inauténtica.

$Y$ en un siglo en que "la apetencia de historia, el saber erudito" y el apego a la verdad, o a la que por tal se tomaba, eran el pan nuestro de cada día, las situaciones históricamente falsas de la novela de moda, hubieron de provocar, como es lógico suponer, copiosas discusiones: ya se ataca con gran encono a Ha novela histórica, ya se toma su defensa: Hugo la hace apasionadamen y no le faltaba razón, pues esa vilipendiada novela histórica es, como dice Menéndez Pelayo "un arte dichoso, que tal sangre vino a infundir en el cuerpo anémico de la historia".

Muy a pesar de críticas y diatribas la novela histórica siguió cultivándose sólo que las falsedades que históricamente se le atribuian desaparecieron con el Realismo.

En América hay también alegatos en torno a este género literario, el poeta cubano-mexicano José María Heredia, "el viejo, el primo mayor del de los Trofeos", la impugna con certeros argumentos, que vienen a

5 Ensayo sobre la novela histórica.

6 Imprenta Universitaria. México, 1947. 
ser como predicar en el desierto ante el auge que en tierras americanas alcanza la novela histórica. México y no casualmente, es el país de mayor producción; las primeras novelas históricas son Jicoténcatl (1827); El Misterioso (1836); Un año en el Hospital de San Lázaro (1841); El Fistol del Diablo (1845) y Gil Gómez el Insurgente de Díaz Covarrubias.

El teórico de la novela histórica en México será Ignacio M. Altamirano; рето de manera bien sencilla, sin meterse en camisa de once varas, Díaz Covarrubias afirma lo que más adelante, en 1868, dirá al maestro: el ideal romántico de la historia es "instruir y deleitar" pues el romántico a diferencia del clásico se dirige al pueblo y ese ideal no es tan descabellado ya que es capaz de otorgarnos un concepto general, más humano que las "historias científicas".

La novela histórica para el novelista veracruzano es un "género útil y en el cual se deben ensayar las fuerzas". "Esta novela - -dice refiriéndose a Gil Gómez es el primer ensayo de ese género; forma la primera página de un libro que dentro de algunos años contendrá bajo un aspecto lo más que me sea posible, la historia de nuestro pais, desde nuestra emancipación de la corona de España, la invasión americana de infeliz memoria. Ahora empiezo por el primer movimiento insurreccionario del cura Hidalgo". "He procurado para la parte histórica, reunir el mayor número de datos y documentos de la época..."

Hay en la obra de Juan Díaz Covarrubias una conciencia por hacer historia verdadera y documentada, por interpretar los hechos; aunque su historia vaciada en el molde romántico venga a ser "historia apasionada a veces objetiva, pero raras veces imparcial; pues cada uno confiesa una creencia, una filosofía, una preferencia política, o un sentimiento de clase, al que se cree que se ilustra o se defiende". "

$\mathrm{Y}$ mientras otros autores tornaron sus ojos a los asuntos europeos para presentar imitaciones de lo medioeval que así salen y a las cuales Altamirano con toda razón critica acibaradamente, Díaz Covarrubias se nutre en lo nuestro, en lo mexicano.

La novela Gil Gómez el Insurgente tiene una trama bien sencilla: un desgraciado cuento de amor en un marco histórico, la lucha por la Independencia de México. El cuento de amor es sólo aderezo para ir diciéndonos sus ideas sobre México, sobre los historiadores; las causas de la Independencia; para exaltar el heroísmo del pueblo.

7 Roger Picard. El Romanticismo social. Fondo de Cultura Económica. México. 1947. p. 212. 
Su estilo posee ya mejores recursos, pero como buen romántico no se cuida de pulir la forma, su interés está en la cabal expresión del sentimiento.

En la novela pueden separarse dos temas: el histórico y el sentimental ; da una mayor importancia al tema histórico, allí quedan expuestos suts juicios sobre México, certeros y penetrantes; analiza el estado político de la Nueva España al tiempo de la Independencia: las diferencias económicas tan notorias; el rico español y sus muchos privilegios; el indio postergado y explotado; el sacerdote más atento a la riqueza y al sojuzgamiento de la sociedad que a sus deberes.

$\mathrm{Y}$ con todo el ímpetu de la juventud y de la pasión romántica los historiadores mexicanos son enjuiciados, Alamán entre otros por presentar ante los ojos del mundo una falsa imagen de México y de sus libertadores; por envenenar el ánimo de la juventud:

"¿Qué podriamos añadir — dice- a lo que han dicho otros escritores como Alamán y Bustamante? Sin embargo, nosotros, jóvenes sin distinciones ni honores, $y$ por consiguiente imparciales, nos atrevemos a hacer un reproche a estos grandes hombres de México. Nos parece que el extranjero que desde lejanas tierras, $y$ por consiguiente, ignorante de nuestro carácter $y$ de nuestros instintos, lea la historia de nuestra revolución por don Lucas Alamán, no puede menos de indignarse contra una colonia tan 'ingrata como México, que recibiendo, según este autor, toda clase de beneficios, de garantías, de civilización de la España osó rebelarse contra ella. Nosotros hemos derramado lágrimas al ver tratados por él a los hombres que iniciaron nuestra independencia, como vagos, ladrones, tahures, ingratos, o aseşinos; mientras que se trata a los dominadores como hombres clementes bondadosos, nobles, que pagaban con actos de generosidad, los crimenes y los actos de atrocidad.

"Es cierto que muchos de los hombres que trabajaron en la obra de nuestra independencia, eran salidos de la hez de nuestra sociedad, es cierto también que entre los españoles había hombres notablemente benéficos; pero eso no forma una regla general $y$ iay! nunca un escritor debe valerse de su reputación para calumniar y poner a los ojos del extranjero, como indigno, a un pais ya desdichado y ya calumniado sin culpa; nunca debe desmoralizar al pueblo hoy desmoralizado ya, mostrándole los crimenes consiguientes a una guerra casi de castas, y no el noble principio que causó su emancipación. 
"El cuadro histórico de México que trazó el eminente patriota D. Carlos Maria Bustamante, a pesar de estar escrito en un estilo sublime que verdaderamente encanta y arrebata, tiene sin embargo el defecto de caer en el extremo opuesto, de exagerar y dar un tinte novelesco a hechos demasiado sencillos, de pintar con colores demasiado vivos una crueldad que en los dominadores no siempre existía.

'D. Lorenzo de Zavala es el escritor más imparcial y más exacto que hemos tenido, y sin embargo, hay en él un espiritu de parcialidad muy ligero, tan leve solamente como el que puede traslucirse en un libro escrito en un destierro, en climas extranjeros, con el recuerdo y las impresiones recientes de persecuciones injustas por enconos de partido.

"Nosotros no profanamos la memoria santa de los muertos. Esos hombres entinentes ya no existen. Nosotros veneramos su recuerdo siempre tierno a nuestro corazón; como escritores, los admiramos y los hemos estudiado: como hombres públicos, los hemos respetado cuando existian, los amamos con ternura; pero desnudados de todo espíritu de partido, amantes patriotas por corazón y por juventud, escritores desinteresados que nunca hemos manchado la limpia reputación de los hombres de mérito por adular un partido crearnos así una popularidad ficticia, creemos y nos atrevemos a decir, que el principal dote de un historiador es la imparcialilad, y más nosotros mexicanos que necesitamos desvanecer las malas ideas que acerca de nosotros se tienen en Europa, ideas esparcidas por ingratos literatos extranjeros que después de recibir en nuestro pais una franca $y$ generosa hospitalidad, nos han vendido como villanos al volver a su patria".s

La historia en la obra de Juan Diaz Covarrubias trata de ser objetiva, para lograrlo la apuntala reciamente con proclamas de los caudillos; edictos contra Hidalgo; describe con toda minucia las atrocidades de la lucha; da a conocer con sus rasgos más destacados a los contendientes ya rebeldes, ya realistas, a Riaño, por ejemplo, le concede valor, honradez. $Y$ la narración es fortalecida con anécdotas, así conocemos la chunga que en verso se hacía a Venegas:

Sombrero, solapa, cuellos,

las botas y el pantalón, todo nos viene anunciando

la hechura de Napolcón.

8 Gil Gómes el Insurgente en Obras Completas. p. 97-98. 
Anhelos de libertad $y$ de idealismo propios del Romanticismo inundan la novela, y es clara la intención de hacer una historia que deshaga los "entuertos" de los historiadores; la mala fe de los extranjeros; de presentarnos ante los ojos del mundo limpiamente; trata de buscar las causas de la guerra, de interpretar los hechos. Y como buen escritor romántico tiene la conciencia de ejercer una misión, para cumplir con este ejercicio escribe su novela que viene a ser uno de los primeros documentos de justificación y defensa de la Independencia de México y una réplica a Lucas Alamán.

La otra parte de la novela corresponde a lo sentimental, aspecto que también trata al modo romántico: el amor frustrado, inalcanzable y cuyo desenlace es la muerte.

El tema del amor en la obra de nuestro poeta es siempre el amor desgraciado, jamás satisfecho.

Los personajes principales están dibujados con gran cariño, Gil Gómez encarna la valentia, está transido de ideales por los que lucha con un heroísmo exagerado; posee gran nobleza y es conscientemente patriota.

Fernando representa fielmente al romántico, de exquisita sensibilidad, con aspiraciones artísticas; melancólico, el autor se retrata, se identifica con este personaje. Páginas enteras de la vida de J. Diaz Covarrubias aparecen al modo romántico en su obra; una de las características del Romantieismo consiste en expresar siempre lo subjetivo, por eso el escritor romántico interrumpe el relato para intercalar opiniones, hacer su autobiografía o por lo menos dejar un episodio de su vida, y es también regla general que alguno de los personajes sea el retrato del autor.

El romántico se cree, se siente un ser superior, nacido en noramala en un mundo incapaz ${ }^{*}$ de comprenderlo; su inconformidad lo lleva entonces a convertir su "yo" en centro del universo, a que sus deseos sean normas de conducta, a hacer lo que le venga en gana, a pisotear prejuicios y esta exageración del "yo" es la que lo conduce a retratarse en los personajes de la historia.

Y el romántico ser superior según su manera de sentir, se trueca en inadaptado, se aisla de la sociedad que no lo comprende; entonces vuelve sus ojos al pasado y se obsesiona con un porvenir más acorde con su sensibilidad, con sus ideales libertarios; procura evadirse de la realidad, en consecuencia, sus personajes no tienen los pies en la tierra, andan por las rubes, viven lejos de lo que acontece en este pícaro mundo, sueñan y viven sus ilusiones, su mundo imaginativo y claro está, al enfrentarse a 
la realidad que es siempre desagradable la encuentran llena de maldad, nunca plácida y alegre, sino terriblemente triste, desesperante, $\sin$ que se la pueda vivir.

En la obra de Díaz Covarrubias están presentes los anteriores rasgos románticos: la exaltación del autor, el interrumpir el relało para dar su opinión, los personajes henchidos de melancolia se mueven en un ambiente desolador que sólo ofrece desencanto, sinsabores, maledicencia. A excepción de Gil Gómez y Fernando Covarrubias, todos los demás son de pálidos rostros, visten miserables ropas, están inmersos en la miseria, huérfanos, sin apoyo, perseguidos constantemente por la fatalidad, por la maldad; sin embargo, no se rebelan pues un espiritu cristianísimo los contiene; esta contención parece influencia de Lamartine que es el escritor romántico que más se advierte en la obra de nuestro novelista.

Siguiendo el gusto romántico las mujeres están fuertemente contrastadas : la niña ingenua, inocente, de placeres sencillos que sucumbe al amor y a la muerte, o lo que es peor que la muerte misma, al desengaño; a este tipo se opone la mujer mundana, pérfida, obsesa por el lujo y que vive, como pez en el agua, en la sensualidad.

También los personajes masculinos están contrastados : el rico es siemyre innoble, sin responsabilidad, mentecato; el pobre es honrado, lleno de altas e inestimables virtudes.

Otro de los rasgos del Romanticismo es su amor a la naturaleza, esta escuela trae "al arte por primera vez - afirma Azorín- la naturaleza en sí misma y no como accesorio... Ha surgido el yo frente al mundo; el hombre se ha sentido dueño de sí, consciente de si frente a la Naturaleza. De esta consideración y de esa afirmación ha brotado una literatura nueva desconocida de los antiguos. Esa es precisamente la obra del Romanticismo"."

El paisaje en la escuela romántica es considerado como escenario, recurso de contraste y de complemento; sirve de pretexto para realzar la personalidad del autor o del protagonista; subraya la situación psicológica : la luz de la luna es prenuncio de tragedia; los sauces, los cipreces que sombrean las tumbas son árboles preferidos; las ruinas dan al paisaje un toque emotivo, misterioso y sobre el paisaje lúgubre, neblinoso flota la meiancolía y la desesperación del alma romántica.

9 Azotin. El paisaje de España visto por los españoles. Col. Austral, 1941. p. 14. 
J. Díaz Covarrubias reproduce este paisaje en su obra; pero algunas veces cuando no hace coincidir el paisaje con sus desdichas lo describe lleno de color, de frescura, la naturaleza ofrece un aspecto exuberante, este tratamiento del paisaje es propio de los escritores americanos acostumbrados a la grandiosidad de la naturaleza.

Ia visión serena, fresca y colorida del paisaje la otorga el novelista en El Díblo en México, donde San Angel está pintado bellamente, de esta misma manera describe el paisaje de Veracruz, se deleita en la descripción sin melancolía, alegre de su ciudad natal, Jalapa, habla de sus paseos, de las serenatas, de las risueñas casas y jardines; "en que se cultivan las flores y los frutos de más hermoso color, más suave perfume, o más exquisito sabor del Nuevo Mundo, desde la rosa reina hasta esa pequeñita que cubre las paredes como un tapiz: desde el árbol gigante del xenecuitl, hasta los grupos enanos de moreras silvestres; desde el sóchil hasta la campánula y la madreselva: desde el ancho y hojoso platanar, hasta el naranjo pequeño". 10

Un importantísimo aspecto del Romanticismo, el de la novela social, es tratado, honda y apasionadamente por Díaz Covarrubias. Este aspecto es, para mí, el más interesante y positivo de su obra.

"Con el Romanticismo - dice Roger Picard-una de cuyas cualidades dominantes es la imaginación, no podía menos de crecer la boga de la novela, bajo todas sus formas, y en particular, la de la novela social. La mayoría de los escritores y artistas de esa época no se contentaban con vivir su vida de poetas, sino que querían ser también ciudadanos, lo que les conduce a las doctrinas, los partidos, las sectas, que nacian entonces por todas partes y se unían a los reformadores sociales, jefes o militantes de las escuelas ide pensamiento económico o político". ${ }^{11}$ Nuestro Juan Diaz se afilia al Partido Liberal.

La novela social se interesa por los desheredados: el pobre, el execrado por la sociedad, el bandido goza de gran simpatía, se le dignifica, se le ennoblece; la mujer caída es defendida vigorosamente pues es víctima de una sociedad que no la permite regenerarse.

El "humanitarismo" es enarbolado con toda la pasión posible por Victor Hugo.

10 Obras Completar. p. 232.

11 El Romanticismo Social. pp. 162-163. 
La novela social se preocupa también por la psicología de los personajes; por el medio ambiente en que se mueven; describe las costumbres; los sentimientos colectivos; las ideologías, y por boca de sus personajes los novelistas sociales expresan conceptos morales sobre la sociedad; hacen critica acibarada de las instituciones, proponen doctrinas reformadoras, e intencionadamente quieren ejercer una influencia sobre el espiritu del lector y hacer algo por la reconstrucción social, de este modo la novela se convierte "en una verdadera tribuna popular", ya que "los románticos crearon no sólo la afición de los lectores a la descripción minuciosa de las condiciones materiales, y morales de la vida, sino que además supieron inspirarle verdaderas ideas o actitudes políticas y despertar su conciencia social". 12

Juan Díaz Covarrubias no permaneció ajeno a este apostolado de los románticos y es asi como lo más importante de su obra es su sentido social que al decir de Altanirano nació de su amor al pueblo, de su bondad inmensa y esta natural bondad llevó a Díaz Covarrubias a escribir novelas como La Clase Media, Impresiones y Sentimientos, en las cuales consigna bastantes artículos de costumbres y escenas mexicanas: El Diablo en $M \dot{e}-$ xico, en estas novelas están patentes los postulados de la novela social, quiere reformar la sociedad que está mal organizada; son una protesta contra las injusticias, contra los desmanes de los ricos, contra la explotación del pobre; la aristocracia es atacada violentamente por su desarraigo, por su desamor a México, desde entonces bien notorio; se desvive por imitar todo lo europeo sin importarle el país; rendida al dinero es motejada como "aristocracia de arlequín, aristocracia de polichinela".

Los personajes en estas novelas son presentados con sus rasgos físicos y psicológicos: bondad, honradez, nobleza, caridad en los pobres; bajos, inescripulosos, con muchos vicios, irresponsables, los ricos. Describe puntualmente el medio en que viven unos y otros, lo que hacen, como distribuyen sus horas. $\mathrm{Y}$ para ello da a conocer los sitios y rincones de la ciudad con su arquitectura, los lujosos palacios de la calle de Donceles; las salas ricamente amuebladas nos dicen lo que entonces se tenía por ostentoso:

"En la sala hay cuanto pueda desear el capricho de un oriental; magnífica alfombra que apaga el ruido de las pisadas, espejos dorados que casi tocan al cielo, lujosa y agradablemente pintado, sillas y sofáes de terciopelo bordado, consolas magnificas, $y$ encima de ellas juguetes y chu-

12 El Romanticismo social. p. 162. 
cherías de porceiana de Sévres, un piano regio, cortinas lujosas que producen una suave luz de lo más agradable, y en cada uno de los rincones estatuas de mármol purísimo de Carrara, que representan deidades mitológicas". 13 No menos suntuosas son las cámaras, el tocador se adorna con "infinidad de frascos y juguetes con pomadas y esencias", los lechos tienen ricos doseles; en los patios hay varios carruajes; los criados son muchos y están vestidos a la francesa.

Toda esta ostentación contrasta con el Barrio de San Salvador y con sus pavorosas casas de vecindad donde la miseria asienta sus reales; da noticia de la vida y suerte de cada tno de los personajes que viven en los destartalados cuartos: el estudiante pobre y su modo de vestir, lo que come, las cátedras a las que asiste "las lecciones del profesor Morales, cuyo nombre - dice- se ha hecho célebre en México bajo el seudónimo de El Gallo Pitagórico"; compañeras de este estudiante son la viuda de un militar olvidado; la infeliz costurera, una joven burlada que encierra el ideal romántico. Alude las diversiones de los pobres; las muchas y costosas de los ricos y sus paseos preferidos, el famoso de Bucareli, el elegante de San Francisco; las temporadas de descanso en San Angel; el mentidero donde los jóvenes de postín se reunen a quitarle el pellejo al prójimo, el café "El Aguila de Oro", café que con el "Veroly" fueron los más concurridos de la época; lo que allí se servía, en el piso superior helados, café y licores; lo que entonces estaba de moda beber, "los fósforos", mezcla de café y licor que ahora llamamos "café con piquete", cafecito que bebemos en los velorios, y para curarse la "cruda" se venden en jarritos en los "puestos de hojas" muy al filo de la madrugada.

Las diversiones de la sufrida y desdeñada "clase media" según el novelista se concretabąn a las tertulias caseras con su indispensable niña que aporreaba el pipno; a los juegos de prendas y loteria; a las argucias de los novios por burlar la siempre burlable vigilancia materna; los apretoncitos de manos y el cambio de cartitas bajo la mesa, el adelantarse en la calle a los padres para ir agarraditos de la mano, en fin toda una serie de diversiones y comportamientos que ya no se estilan, pero que indudablemente tienen su gracia y encanto.

También destaca los tipos que deambulan por la ciudad de México: toda una gama de desheredados; los distintos ricos : el usurero, lógicamente avaro, el hacendado, el adinerado español don nadie en su tierra y en México importante y aristócrata en virtud de su casamiento con heredera

13 Impresiones y Sentimientos. p. 107. 
criolla; el español abarrotero que es a la vez prestamista, sus mañas para explotar la miseria de los que a él recurren; las mujeres de sociedad; las celestinas; las beatas son objeto de un detenido y minucioso examen, cuenta sus idas $y$ venidas al templo, su afición desmedida al chichisbeo, las deformaciones que hacen de la religión, su terrible egoismo., Pepito Alfeñique el elegante del barrio enamorado de sí mismo que cambia a cada tarde, traje y bastón.

Los tipos que más interesan a Diaz Covarrubias son los desheredados; pero entre estos hay uno que le arranca los conceptos más sinceros, más doloridos y la impotencia de no poder hacer nada por él lo desespera : el indio, a quien defiende ardorosamente, a quien no quiere ver relegado, discriminado, sino formando parte de la Nación.

El indio es visto al sesgo del molde romántico: es mejor que nosotros pues ha vuelto a la naturaleza, no está contaminado de civilización, por eso, a pesar de las injusticias y vejaciones que sufre no se rebela, no se venga; posee todas las cualidades.

$Y$ las acusaciones que lanza contra los que explotan al indio aun son válidas, aun son actuales, pues muy a pesar de la propaganda, el indio sigue viviendo en las mismas condiciones miserables, se le explota igual, la novela de nuestro días Resplandor de Mauricio Magdaleno vuelve a repetir la protesta de Díaz Covarrubias.

"Y en medio de este caos revolucionario Clama- ¿qué ha sido de tí pobre indio? ¿Qué se ha hecho por tu existir social? ; Nada, absolutamente nada! ha continuado tu vida de agonía y esclavitud, Tú llevas en tu ser los gérmenes para formar un pueblo honrado, laborioso, civilizado; pero te han relegado al olvido civil $y$ te han negado el derecho de ciudadanía ; víctima de la tirania de un mal juez y la codicia de un mal sacerdote se ha traficado con tu sangre y con tus lágrimas. Esclavo de un propietario rico y cruel, tu vida ha continuado casi tan espantosa como en la dominación española. Hijo de la degradación y el servilismo la desgracia te ha hecho supersticioso cerrando tu corazón a los afectos dulces de la vida, te has vuelto a la naturaleza, y cansado de la ingratitud de los hombres, tus hermanos, has consagrado toda tu ternura a los objetos. Hasta tus cantos populares respiran esa tristeza. desconsoladora que te consume. . "14

Los anteriores párrafos de Díaz Covarrubias son un jirón del proceso histórico del indio que aún está por estudiarse.

14 Discurso prontunciado en la ciudad de Tlalpan en 1857. Tipografía de Manuel Castro, 1860, p. 14. 
Una obsesión, una angustia, consume al poeta: el porvenir de la patria que se está constituyendo en nación; las ideas del tiempo que recoge el Gallo Pitagórico así como otros escritores no pasan inadvertidas para el joven poeta ; $y$ como hace el verdadero historiador que se pregunta por el destino y que al estudiar el pasado se desplaza hacia el futuro y se torna profético, Díaz Covarrubias muestra claramente su intención reformadora, reconstructiva; se pregunta casi con un nudo en la garganta: ¿Qué va a ser de México en medio de tantas calamidades, de tan sombrio panorama: guerras, cuartelazos, la odiosa e inhumana leva, la inicua explotación del miserable? $Y$ ante este desastre que agobia a la patria propone una fórmula: paz, unión y trabajo y envia un mensaje clarividente que no ha perdido actualidad, sus consejos aun son valederos, quiere que se cumpla un buen programa para que México prospere y la salvación del pais está en un gobierno republicano que cumpla estas atinadas proposiciones :

"Que se prefiera a los hombres talentosos y honrados; se cuide minuciosamente de la educación y los indios, planteando numerosas escuelas, que los legisladores y diputados en vez de decir hermosas palabras, velen por la felicidad y conserven los intereses del pueblo que los envia al Congreso; que el propietario ampare a los indios y a sus obreros y contribuirá al bienestar y progreso de la nación. Que la agricultura y la mineria yerdaderas fuentes de riqueza del país, encuentren protección del gobierno, que se fomente la colonización, que se arregle la propiedad; que el camino de fierro atraviese desde el Istmo de Tehuantepec hasta las llanuras de Sonora, desde el Qcéano Pacífico hasta los puertos del Golfo de México ... Que no se descuide tanto la educación de la mujer y se recogerán provechosos frutos y palpables resultados".

"Que los hombes en vez de formarse una profesión en la política, se hagan científicos o artesanos... Que la prensa en vez de ser órgano de persecuciones y centro de ridículas cuestiones privadas, de insolencias y de parodias, sea fuente de luz donde se discutan intereses nacionales... $Y$ este cuadro no es ilusión del deseo y la esperanza ... i El porvenir espera! ${ }^{15}$

En la obra de Juan Día Covarnubias podemos señalar la imaginación y sus mejores recursos de lenguaje que hacen dar un paso más adelante a la novela mexicana; pero sus valores más positivos son, desde lue-

15 Discurso. 15-16. 
go, su mexicanidad, su sentido histórico, su sentido social, sentido este último que ha llegado a ser una de las características más destacadas, más loable y estupenda de la novela mexicana contemporánea ¿ pues qué otra cosa sino cálidas y airadas protestas contra la injusticia, contra la avidez de los los poderosos y de los malos políticos son las novela de Mariano Azuela, de Martin Luis Guzmán, de Mauricio Magdaleno? y cuyo germen se encuentra ya en estas sencillas páginas de Diaz Covarrubias y cuyo mérito dice atinadamente el Viejecito Urbina al comentar la obra del malogrado escritor y la de Luis Rivero y Río "está en la pintura del medio aquel, hecha a la manera romántica, por supuesto, con un subjetivismo visionario, y en la reproducción de las ideas y sentimientos imperantes.

"Porque se prolongaba y acentuaba la tendencia a nacionalizar la literatura, a dibujar nuestros paisajes, revivir nuestra historia y presentar y estudiar nuestra humanidad". ${ }^{16}$

Si el romántico vió al mundo desde la puerta auténtica del sentimiento, el realista lo ve con la observación directa de lo cotidiano. Su meta: la exacta y fiel reproducción de la vida hecha minuciosamente, casi como un inventario, siempre desde fuera haciendo todo lo posible y lo imposible porque su personalidad y sus sentimientos no intervengan, impasiblemente.

$Y$ como el amor a la verdad es una de las consignas a que obedece el escritor realista sacrifica a este amor la belleza. El realista es cerebral, sensual y su forma, en contraste con la romántica, cuidadosa; escribe de manera más lenta que clásicos y románticos y al igual que estos últimos tiene una finalidad distinta a la escritura misma, busca el ejercicio de un apostolado; se siente también reformador de la sociedad. De aquí que toda razón asista a Rafael Delgado cuando afirma: "Romanticismo y Realismo no son términos antitéticos" pues los realistas siguieron trabajando sobre los temas románticos con mayor hondura: cultivan la novela histórica de manera tan erudita que "las infidelidades históricas son más bien caídas, composiciones intencionales. Inevitablemente, del buscado tratamiento histórico de la novela gracias a las corrientes literarias realistas y a las tenaces exigencias de la crítica nunca bastante satisfecha de la fidelidad

16 Luis G. Urbina. La Vida Literaria de México. Colección de Autores Mexicanos. Editorial Porrúa. México, 1946. p. 108. 
histórica, se pasa al tratamiento confesadamente arqueológico y profesoral ..."17

Continúan laborando sobre los temas de la novela social romántica: la sociedad, los vicios, la política, la moral, la influencia del medio ambiente sobre el individuo; como consecuencia del materialismo que se adentraba en las ciencias, en la filosofia, en la literatura, el dinero es el eje en torno al cual se mueven los personajes realistas. Asimismo estudian al desheredado, la herencia biológica y la religión; lo social se vuelve una constante en el realista.

Los asuntos del realismo como los del romanticismo tienen un carácter nacional, el realismo subraya este acento en el regionalismo o costumbrismo, derivación del gusto romántico por el color, por lo pintoresco.

Esta escuela tiene en nuestro pais entre sus principales representantes a José López Portillo, Emilio Rabasa y Rafael Delgado "que reflejan -al decir de Margarita Pérez Poiré- el realismo en su nejor aspecto: presentación de caracteres regionales, minuciosidad en la descripción de costumbres, color local, americanismo en uma palabra". 18

A esta escuela pertenece Cayetano Rodríguez Beltrán. Nació en Tlacotalpan el 24 de septiembre de 1866, murió en 1939. Su vida transcurrió entre Jalapa y Tlacotalpan. Fue periodista, tenedor de libros, sobre todo, educador; jarnás se decidió a abandonar su terruño " cercano y seguro albergue de ni vejez" reza la dedicatoria de su novela Un Ingenio.

Escribió vatias obras con el anagrama de Onateyac: dos novelas Pajarito (1908) y Un Ingenio ( 1923 ); Cuentos y tipos callejeros; Cuentos Costeños, Perfiles del Terruño y una colección de artículos Atrevimicntos... sliterarios?. López Portillo dice de esta colección que tiene "alteza de ideas, profundidad $y$ una muy cuidadosa preparación cientifica $y$ literaria lucen y resplandecen en esa serie de breves ensayos para honra y prez de su autor"..En esta obrita Rodríguez Beltrán expone a fondo sus ideas acerca de la escuela realista, hace la distinción entre realismo y naturalismo con el que no comulga de ninguna manera, explica cuales son las finalidades de la novela realista, sus temas y las cualidades del novelista:

"Ia novela moderna - afirma- es realista, afiliada a la escuela especulativa del positivismo, e inspirada en estudios psicológicos y sociológicos de antropología honda y precisa ... En la novela de hoy se estudian

17 Ensayo sobre la novela histórica. p. 128.

18 Margarita Pérez Poiré. Don José López Partillo y Rojas. Su vida. Su obra. México, 1949. 
los fenómenos del espiritu, las ranciedades de las costumbres, los productos de un medio ambiente viciado, para buscar la panacea, que modifique ese mismo medio y cure el producto transformándolo, haciéndolo de otra manera; en la novela moderna no se vienen a analizar vicios de conformaciones ante una plancha de anfiteatro, ni enfermedades exóticas como en una sala de clínica; porque la humanidad está ya harta de ver retratadas sus deformidades físicas, y vive curiosa de conocer sus alteraciones psicológicas, la herencia, las costumbres, la asociación, el atavismo, etc., etc., son problemas de estudio que bien encajan en la novela, que es el libro más leido y más traido desde que apareció "Periquillo Sarniento" hasta que se prohibieron en los hogares las novelas de Paul de Kock".

"El novelista ha de tener la observación del historiador, la profundidad del pintor: ser artista en toda la acepción sublime del vocablo: verídico, real, sugestivo; no como los autores de esas novelas del siglo pasado, que queriendo aparecer intimos resultaban poco conformes con la realidad ... ${ }^{\text {1日 }}$

En estos párrafos Rodríguez Beltrán se afilia al realismo y es, desde luego, un escritor fundamentalmente realista; su novela Pajarito está dedicada a López Portillo y a Rafael Delgado; recordemos como José López Portillo llama maestros a los españoles Pereda y Palacios Valdés ; la dedicatoria de Rodríguez Beltrán muestra, muy a las claras, su ascendencia, su vínculo con el realismo español; de donde viene y lo que pretende hacer. La influencia más notable en stı obra es seguramente la de Pereda.

Los Cuentos Costeños aparecen en 1905 con un prólogo muy elogioso de José López Portillo quien le otorga con toda razón el título de costumbrista. Cuentos y tipos callejeros (1922) en ellos el autor no logra su objeto porque la trama, la anécdota, es muy débil; los personajes no son relevantes, salvo los de carácter costumbrista, el interés está en la parte pintoresca ; en cambio, las estampas de los "tipos callejeros" son magníficas porque están dentro del costumbrismo puro que Rodríguez Beltrán sentía, le gustaba, sabía hacer.

La más conocida novela de este autor es Pajarito, novela hecha sobre un personaje del mismo nombre, cuya vida trata de contar y que no tiene nada de interesante. El ir y venir de la novela es el tema realista de una herencia.

19 Cayetano Rodríguez Beltrán. Atrevimientos... diterarios? Tipografía "La Reforma". Tlacotalpan. 1900. pp. 68, 69, 70. 
Pajarito hijo natural de un español, crece formado por su madre en la clase humilde a la que ella pertenece. Muerta la madre muchos años después, ya hombre más que maduro, la novela vuelve a hablarnos del padre, ahora rico y a quien bien tarde le entran los escrúpulos, busca a Pajarito, interviene un tinterillo que enreda las cosas. Al reconocimiento de Pajarito se opone el sobrino del viejo, un español que ha trabajado con él. Cuando don Javier de Illescas está casi moribundo el tinterillo lleva a Pajarito, el padre lo reconoce como hijo; pero no logra la herencia. Pajarito muere y su hijo sigue tratando se le dé algo de dinero, por fin, logra doscientos pesos.

La novela tiene una gran falla; no la trama que esta no importa, sino el tratamiento del personaje, pues si la novela está trabajada sobre un sólo personaje, este debería tener muy bien trazado su carácter, sus rasgos psicológicos bien definidos, en suma, dimensión y en la novela de Rodriguez Beltrán el personaje nada tiene de esto; los otros personajes tampoco tienen hondura, valor, construcción psicológica, defecto común a la mayor parte de los realistas españoles y mexicanos que no pasan nunca de la superficie, que no se adentran en los personajes.

Sin embargo, lo que si encontramos y es interesante que a pesar de tales defectos, los personajes mejor trazados en los que se detiene el autor son los de las clases populares de Tlacotalpan y Veracruz donde la novela'acontece. Rodríguez Beltrán sentía en verdad al pueblo; es cierto que sus personajes no tienen profundidad, hondura, que no viven su vida, su drama, que son siluetas, que no supo darles dimensión, pero los dibujó siempre con dêtenimiento, con cuidado, sobre todo con cariño, tiernamente; en cambio los otros personajes como los ricos españoles, un cura y algunos otros sop más débiles que los de carácter popular, vistos muy superficialmente $y$ algunos como el tinterillo Sancho Sánchez de la Sancheta es francamente caricaturesco; es claro, que quiere censurar, pero se le vueive demasiado grotesca la caricatura.

Ya he dicho que es una novela de poca hondura, las ideas que allí se encuentran son superficiales, tienen la intención de censurar ciertas lacras, vicios, a tipos como el tinterillo, al español entregado en cuerpo y alma al dinero; la censura es débil, expresada muy por encima. Tesis ninguna, no se inclina ni para un lado ni·para otro, no censura, no justifica, se concreta a exponer.

Los sentimientos son también muy sencillos, simples: el amor filial, el maternal, el amor, son enfocados desde el punto de vista romántico, sin 
que por esto la novela sea romántica, sentimental; no existen complicaciones, el amor es el amor; los celos son celos, el pan, pan y el víno, vino. Ahora la novela presenta su aspecto más valioso: el ambiente, el paisaje, el marco, son de primerísima calidad. El ambiente está tratado con descripciones, le interesa mucho hablar de las bellezas del paisaje; es preciosa la descripción que hace de los alrededores de Tlacotalpan, de su río; describe la ciudad; muestra mintuciosamente el interior de la casa de un albañil en Tlacotalpan y tiene un verdadero, un gran deleite al hablar de los paseos, de las fiestas, del banquete el dia de las bodas, ennumera los platillos regionales, la gran variedad de dulces que ese dia se preparan: "La sopa borracha por delante, bañada en almíbar y espolvoreada de canela; a esta la siguieron los chongos jalapeños tostados y melosos, la sopa del cielo cuyo solo nombre es indicio y clave de lo subido del condimento, los merengues de leche que no hostigan ni empalagan $y$, para cabal punto de la comilona, se sirvió la conserva de coco con pasta de aimendras, el postre clásico de las bodas jarochas". 20

Rodríguez Beltrán era un auténtico y neto costumbrista, estas descripciones de intenso costumbrismo podrían aislarse y serían por sí inismas verdaderos y magníficos cuadros de costumbres. Por ejemplo, aquella tan viva y movida descripción de los pleitos de los muchachos "arribeños" y "abajeños", que cuenta como por la reciente guerra de intervención que llevó a Veracruz el cuartel general de las fuerzas liberales, eI espiritu bélico de los párvulos se había exacerbado y buscaba salida.

$Y$ aunque Pajarito no es novela histórica, por esta descripción que capta el espiritu de la generación que siguió a la caída de Maximiliano, Lloyd Read la incluye en su obra The Mexican Historical Novel y dice: "El espiritu de esta época destaca bastante en algunas partes de la obra para justificar el incluirla dentro del grupo histórico... La manifestación más interesante del estado de la mente en esta época de la historia mexicana en la descripción de los juegos de los niños. E1 autor pinta niños pequeños ocupados en jutegos militares marchando, ejecutando numerosas maniobras, improvisando batallas y combates, peleando con imaginarios enemigos con palos a manera de rifles durante las horas de recreo en las escuelas para preparar la defensa y un ataque estratégico ... Ciertamente en pocas novelas la preocupación emocional de una generación ha sido tan bien analizada en las actitudes de los niños. Pajarito en este aspecto es de-

20 Cayetano Rodriguez Beltrán (Onateyac) Pajarito. Eusebio Gómez de la Puente Editor. México, 1908. p. 365. 
DOI: http://dx.doi.org/10.22201/iie.18703062e.1952.20.529

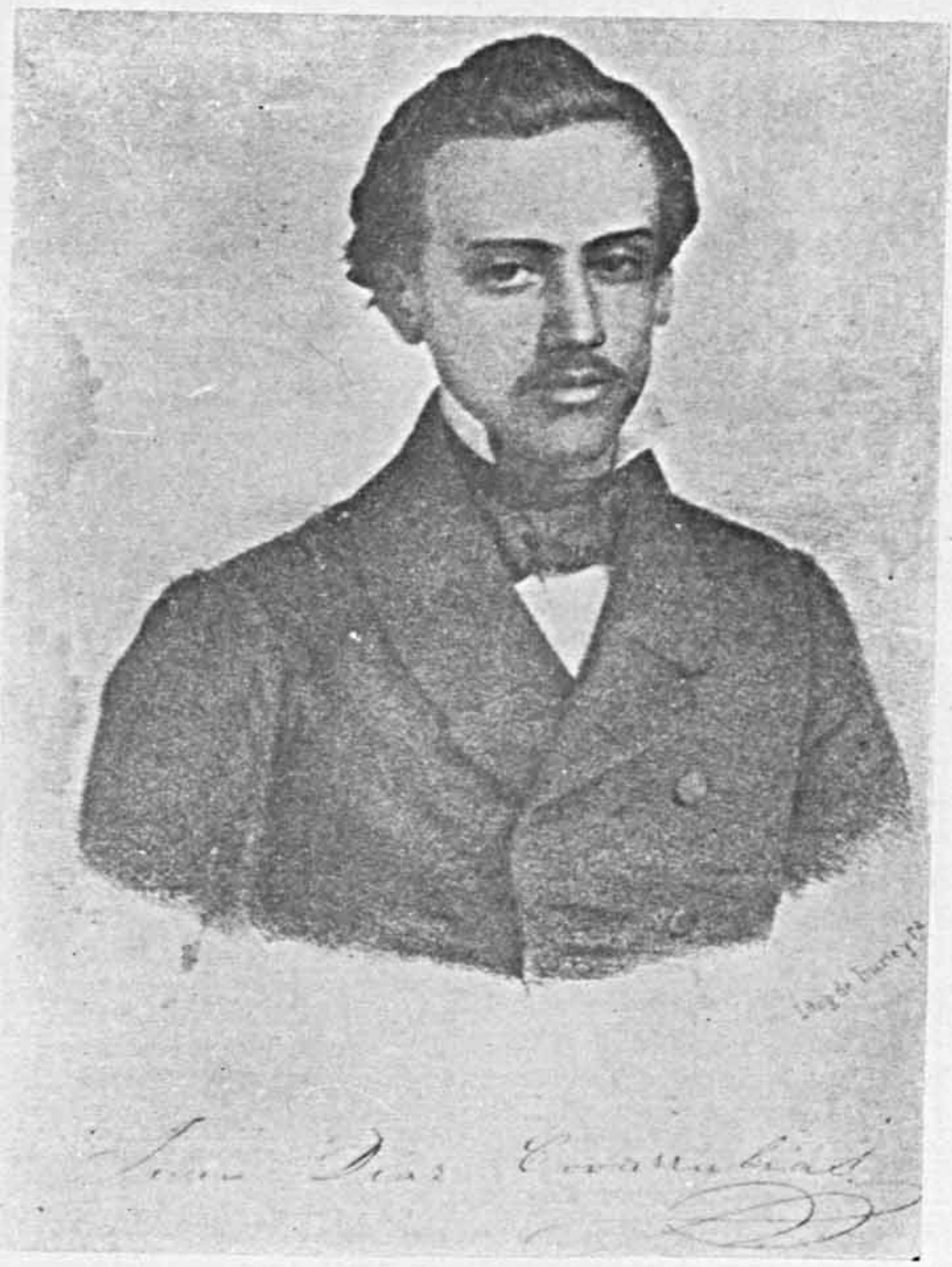

1. Juan Diaz Covarrubias. 
DOI: http://dx.doi.org/10.22201/iie.18703062e.1952.20.529

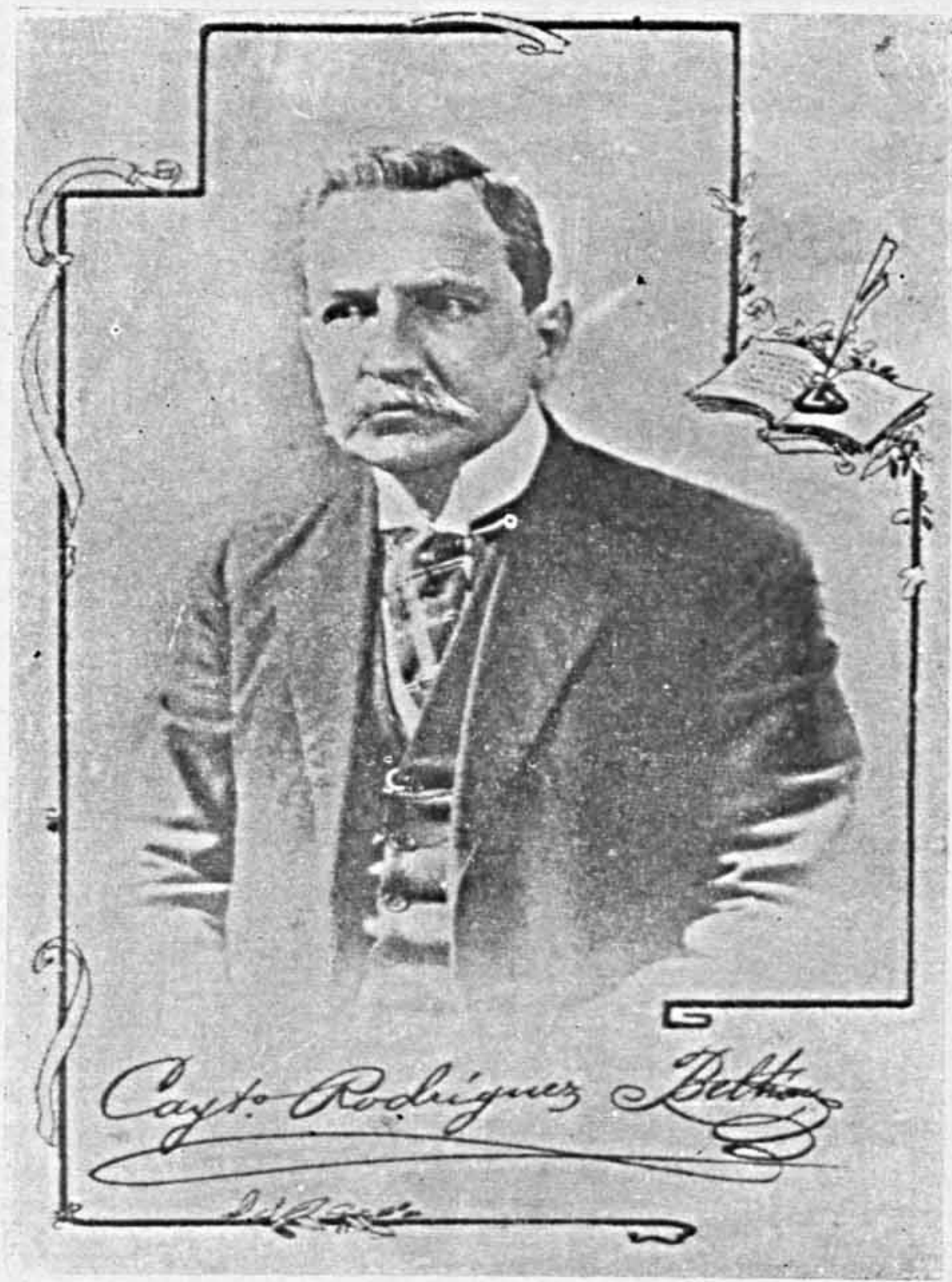

2. Cayetano Rodríguez Beltrán. 
masiado atractiva... Estudios sociológicos serios de este espiritu de pandilla entre los jóvenes han sido escritos con menos penetración que el de Rodríguez Beltrán... y está realizado con una gran naturalidad". 21

EI estilo de Pajarito está tratado a la manera realista, es decir, hacer que el lenguaje en los diálogos corresponda al personaje, lo cual es de gran importancia desde el punto de vista del costumbrismo y la filologia. Cuando el autor habla por sí mismo usa un estilo que a veces recuerda demasiado al de los escritores españoles de la época: peca de purismo, usa una serie de locuciones muy castellanas, demasiado castizas, se muestra españolizante, en cambio, cuando hablan sus personajes se revela como un verdadero maestro en el manejo del lenguaje vivo, familiar, popular de la región, aqui radica su importancia, encontramos muchos regionalismos, no sólo los que se señalan como tales en el apéndice de la novela sino además de las palabras aisladas, modismos, dichos, proloquios, formas sinfácticas populares, en resumen, el lenguaje popular regional está perfectamente captado y este aspecto de la novela se convierte en documento, pues conserva una fuente para conocer el lenguaje que el pueblo hablaba en la región hace más de un siglo.

Los filólogos especializados pueden encontrar en Pajarito un inestimable material de estudio. Rodríguez Beltrán aprovecha también muchos elementos folklóricos, registra sones veracruzanos, coplas, versos de la hoy tan gustada bamba, que se deriva de la clásica copla de seguidilla con el estribillo propio:

Pa cantar la bamba
se necesita
una poca de gracia
y otra cosita...
A muchos no fes gujta
la cinta blanca
porque dicen que e trijte
y a mi me encanta...
Arriba y ma arriba
arriba iré
repiquen las campanas
repicaré...

21 J. Lloyd Read. The Mexican Historical Novel. Instituto de las Españas en los Estados Unidos. New York. 1939. p. 304. 


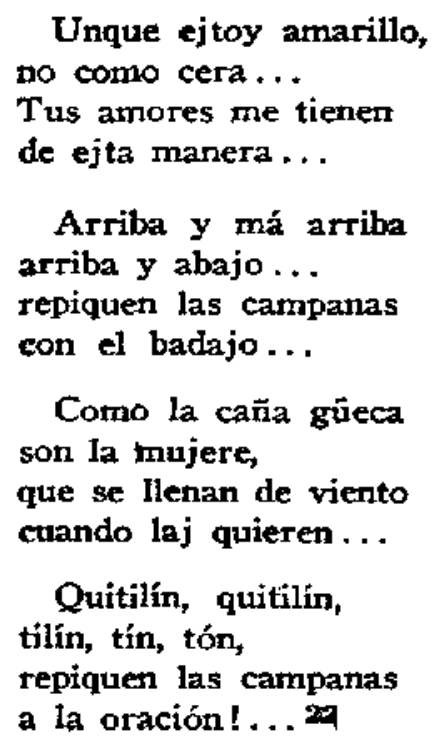

Resumiendo, los valores más importantes y valiosos de Pajarito son las escenas, el ambiente muy bien tratado; lo costumbrista realizado de manera admirable; casi podría afirmar que hubiera sido preferible que cultivara exclusivamente este género.

Pajarito sigue teniendo un valor: más que las descripciones generales hace vivir y conserva ese ambiente popular de su época; el habla popular que es lo más vivo y emotivo que un pueblo tiene, hasta convertirlo en un documento de auténtico interés no sólo folklórico sino histórico.

Estas misma excelencias costumbristas de Pajarito se repiten y otorgan valor a su obra $P$ erfiles del Terruño, donde enmarca en ameno cuadro la vida y las costumbres de su tierra natal: los habitantes, las casas y su arquitectura; los floridos patios; los calles, el mercado; los servicios públicos; el paisaje embellecido por el Papaloapan; los paseos, las fiestas; los juegos de niños, las fondas y lo que en ellas se come y se bebe, como se acostumbra vender el sabroso pan; los cantos populares y todos los tipos que en Tlacotalpan deambulan; no se le escapa ni el borrachito del pueblo; el modo peculiar de hablar. de los tlacotalpeños y hasta los fieles y sufridos perros son recordados.

$\mathrm{Y}$ es así como una parte de este nuestro México enorme y múltiple y distinto en cada región fué retratado con toda maestría por Rodríguez Beltrán.

22 Pajarito. 474-5. 
No tiene interés enfocar como novelista en el marco de la Literatura Mexicana a Cayetano Rodríguez Beltrán, pues su interés y valores positivos, nada desdeñables, son la intención de dar a conocer su tierra y a sus habitantes, conservar en sus textos todo un cuadro de conjunto, un vasto $y$ animado cuadro de la vida de varias regiones de Veracruz a mediados y a fines del siglo $x i x ; y$ como a medida que pasa el tiempo, las costumbres cambian, estos documentos acrecientan su valor pues el estudio que los costumbristas hacen de la realidad que los circunda al modificarse las costumbres adquiere un gran valor, un enorme interés histórico.

Ya desde los días de la Ilustración el hombre se preocupa en buscar que es lo típico del hombre a través de sus variedades, el hombre en general, en suma "la humanidad"; como vive, lo que cree, los ideales estéticos y religiosos, los métodos de enseñanza, lo que come y lo que bebe, todo esto es clave, indice para conocer al hombre; Voltaire con esta finalidad escribe su célebre Ensayo sobre las costumbres y en el siglo romántico Honorato de Balzac, el más conspicuo de los escritores realistas es de hecho un espejo del tiempo, una historia de las costumbres.

En México, entre otros muchos escritores, Fernández de Lizardi, Tomás F. Cuéllar, Juan Díaz Covarrubias, Manuel Payno, Angel de Campo y Cayetano Rodríguez Beltrán hacen historia ya que como escritores costumbristas muestran fla vida del mexicano, sus gustos, sus sentimientos, las creencias y las idas; las modas y el arte, cómo ama, cómo sufre, cómo se divierte, lo que suele comer y beber. Pongamos un ejemplo, cuando los historiadores venideros lean en los textos literarios como las bebidas nacionales y la "muy francesa historia del cognac" fueron desplazadas por la "muy anglosajona historia de wisky" confirmarán la infuència anglosajona que nuestro pais sufrió. $\mathrm{Y}$ aquí cabe una pregunta zqué bebida tendrá primacía mañana?

Las costumbres son temporales, cambian según los tiempos y de este cambio nace su valor histórico, pues cada tiempo tiene sus necesidades espirituales, sentimentales, intelectuales, de donde se derivan las materiales $y$ en los autores costumbristas nos damos cuenta no sólo de las exterioridades ya que los cuadros de costumbres son para ver como vive 
el hombre; pero también, más a fondo, para comprender su ser histórico; las costumbres son procesos de la vida del hombre y por tanto, procesos históricos, de aqui podemos deducir el mérito y el valor que para la Literatura y la Historia de nuestro pais tienen los costumbjistas entre Ios que ocupa lugar señalado Cayetano Rodriguez Beltrán. 